\title{
Social influences on the duration of antibiotic treatment of clinical mastitis in dairy cows
}

\author{
J. M. Swinkels, ${ }^{* 1}$ A. Hilkens,† V. Zoche-Golob,‡ V. Krömker,† M. Buddiger, ${ }^{*}$ J. Jansen,§ and T. J. G. M. Lam\# \\ ${ }^{*}$ GD Animal Health, 7400 AA Deventer, the Netherlands \\ †Department of Social Sciences and Strategic Communication, Wageningen University, 6700 EW Wageningen, the Netherlands \\ †Department of Bioprocess Engineering and Microbiology, Hannover University of Applied Sciences, D-30453 Hannover, Germany \\ $\S$ St. Anna Advies, 6525 ZM Nijmegen, the Netherlands \\ \#Department of Farm Animal Health, Faculty of Veterinary Medicine, Utrecht University, 3584 CL Utrecht, the Netherlands
}

\section{ABSTRACT}

Clinical mastitis of dairy cows is a visible inflammation of the udder, which is usually caused by bacteria and treated with antibiotics. Although pressure is increasing to reduce antibiotic usage in livestock in the European Union, feedback from the field suggests that clinical mastitis treatment is frequently repeated after the initial per-label treatment, thereby extending treatment duration. The aim of this study was to explore the social factors influencing farmers' decision-making on the duration of antibiotic treatment of clinical mastitis. In total, 38 dairy farmers in the Netherlands (n $=17)$ and Germany $(\mathrm{n}=21)$ were interviewed in a qualitative semi-structured way. Extended treatment was defined as any treatment longer than that given in label directions. Of the 38 farmers, 30 reported routine and 7 occasional extended antibiotic treatment. The interviewed farmers were sensitive toward social norms of other farmers and recognition for good stockmanship. Extended treatment is perceived as part of the social norm of "being a good farmer." The participants' perception was that mastitis is not treated "thoroughly" if clinical symptoms were still visible at the time of cessation of treatment, because it may persist or recur. As a result, treatment was frequently extended by repeating the initial label treatment. Farmers, specifically the more "cow-oriented" farmers, expressed insecurity on how to treat mastitis effectively. This insecurity made them more sensitive to comply with other farmers' injunctive ("what ought to be") and descriptive ("what is done") norms and the perceived veterinarians' informational norm that extended treatment is better, resulting in an approved social norm. Social approval reduces the insecurity of being perceived as a poor farmer; thus, extended treatment is emotionally rewarded. This social reward apparently outweighs the higher costs of more

Received June 13, 2014.

Accepted December 19, 2014.

${ }^{1}$ Corresponding author: j.swinkels@gddiergezondheid.nl waste milk and more antibiotic usage. Perceived positive reference groups with whom the farmer identifies and regularly communicates face to face, such as other farmers, the herd veterinarian, and other farm advisors, confirm the farmer's judgment on extending treatment and influences him or her toward socially accepted behavior. Society was the most negative reference group, barely influencing farmers' decision-making on treatment. The emotional gap between farmers and society is large and probably difficult to overcome. Legislation may reduce antibiotic usage, if doable and controllable. Evidence-based information on treatment efficacy or practical on-farm decision support indicating when to end treatment may be able to change social norms of "thorough" treatment, especially when communicated by a positive reference group such as veterinarians. Because prudent antibiotic use is hindered by perceived subjective norms on optimal duration of antibiotic treatment, more research is needed, particularly on the optimal duration of antibiotic treatment of specific pathogens as related to cure and recurrence of clinical mastitis.

Key words: dairy cow, clinical mastitis, antibiotic treatment, social influence

\section{INTRODUCTION}

Mastitis is a painful inflammation of the udder of dairy cows that is usually caused by bacteria. On dairy farms, antibiotics are mainly used when cows are dried off and to treat clinical mastitis cases. Recently, antibiotic use in livestock, including dairy, raised national political concerns in the Netherlands. In Germany, the discussion to restrict the use of antibiotics in livestock is currently ongoing, whereas in the Netherlands, quantitative goals to reduce antibiotic use in livestock have already been set. In both countries, preventive use of antibiotics is now forbidden. In the Netherlands, this has resulted in the introduction of selective dry cow treatment, allowing antibiotics to be used at drying off only in cows with intramammary infections (Scherpen- 
zeel et al., 2014). Apart from dry cow treatment, further antibiotic reduction in the dairy industry could be achieved by changing dosage or duration of treatment of clinical mastitis. Feedback from the field, however, suggests that clinical mastitis treatment protocols are frequently repeated after the initial on-label treatment, thereby extending treatment duration. However, although some studies show a beneficial bacteriological effect of extended treatment (Sol et al., 2000; Oliver et al., 2004; Krömker et al., 2010; Truchetti et al., 2014), the results are conflicting. Some studies did not find a favorable bacteriological effect of extended treatment for Staphylococcus aureus (Swinkels et al., 2013a), whereas others did (Truchetti et al., 2014) or showed pathogen-specific bacteriological effects in streptococci (Swinkels et al., 2014) or only an effect on clinical signs (Swinkels et al., 2013a,b). There appears to be an effect of the type of antibiotic used, the pathogen involved, the duration of infection, farm epidemiology, and possibly other factors. The limited scientific data on the benefit of extended treatment suggests that it may not always be necessary and requires evidence-based decisions.

Because of the additional associated costs and the mounting pressure in the European Union to reduce antibiotic use (EMA, 2014), it is relevant to explore why so many farmers extend mastitis treatment. Understanding what influences decision-making on the duration of treatment requires insight into farmers' perceptions toward treatment, specifically toward the duration of mastitis treatment.

Human behavior, such as extending treatment, is shaped by social interactions between different people (Leeuwis and van den Ban, 2004). Thus, a farmer's decision to extend treatment is not taken in isolation but is influenced by others. It has been reported that farmers are influenced both by other farmers (Friedman et al., 2007) and by veterinarians (Jansen et al., 2010). However, little is known about how farmers are influenced and about the role of other actors within their direct social circle. The objective of studying social influence is to understand and explain how the thoughts, feelings, and behavior of individuals are influenced by the actual, imagined, or implied presence of others (Turner, 1991).

The presence of social norms and social uniformities among the members of a social group arise from their interaction and relationships. Such social norms express social values (different subjective aspects on "what is believed the majority does or feels") as well as normative judgments (psychological commitments to "what ought to be," reflecting the consequences of not complying with the rules of the community; Hechter and Opp, 2001; Bicchieri and Muldoon, 2014). Violation of the norm will result in social sanctions. The theory of social conformity states that if a group of people agrees and shares an attitude, that attitude has (subjective) validity (Cialdini and Goldstein, 2004). Group pressure makes such attitudes and beliefs stronger. Theories of social comparison processes imply that people have a need to compare with others to evaluate their opinions and abilities (Cialdini and Goldstein, 2004). Collective wisdom tends to serve the individual and the group as well. In addition, people prefer to compare themselves with more similar others. The more similar the others are, the higher their social influence is, and the greater the tendency is to reduce differences (Festinger, 1954). Social influence theory distinguishes normative influence, when trying to conform to positive expectations of others, and informational influence, when trying to obtain information about objective reality (Deutsch and Gerard, 1955). In normative influence theory, injunctive norms ("what ought to be") and descriptive norms ("what is actually done") both play a role. The essential difference between the two is that injunctive norms involve social sanctions for noncompliance with the norm, whereas descriptive norms do not (Lapinski and Rimal, 2005).

Qualitative research on perceptions of farmers tries to describe, interpret, and understand their experiences and choices through personal interviews. This qualitative research enables us to encapsulate the entire spectrum of the farmers' social environment that influences their behavior (Cialdini and Goldstein, 2004). Qualitative research allows us to study how social influences are created and given meaning (Denzin and Lincoln, 2000). Understanding social influence seems to be a prerequisite for effectively influencing behavior and may be hard to detect if only prewritten quantitative surveys are used. Qualitative research on perceptions of farmers toward treatment of clinical mastitis from the perspective of social influence can provide helpful insights into the reasons why farmers extend treatment and thus can contribute to our knowledge on how to influence behavior toward reduced antibiotic use on dairy farms.

The aim of this study was to explore social influences on decision making of farmers on the duration of antibiotic treatment of clinical mastitis of dairy cows in the Netherlands and in Germany by qualitative research using personal interviews.

\section{MATERIALS AND METHODS}

\section{Selection and Description of Farms}

The target population of this study was nonorganic dairy farms not involved in milk processing (only 
primary production), with a herd size of at least 50 cows in the Netherlands and Germany (North RhineWestphalia and Lower Saxony) and a perspective of continuity, expressing the intention to stay in business for at least 5 more years. A census of dairy farmers of the Netherlands and Germany was obtained from the Dutch national and German regional databases, respectively. Sixty farms were randomly selected from the databases of each country. Seventy-two farms were contacted by telephone or personal visit to explain the purpose of the study (the Netherlands: 34 farms; Germany: 38 farms). Of the contacted farms, $50 \%$ and $45 \%$, respectively, agreed to participate, leading to 17 farms from the Netherlands and 21 farms from Germany involved in this study. This number of farms was considered sufficient based on earlier reports that after approximately 12 (Guest et al., 2006) or 20 (Green and Thorogood, 2009) interviews, responses would start to repeat themselves. Average herd size of the Dutch and German herds was 89 and 88 dairy cows, respectively, with average 305 -d production of 8,930 and $9,150 \mathrm{~kg}$ of milk. This average herd size and 305-d milk production were somewhat higher than the national or regional averages of Germany [74 dairy cows/farm, $8,802 \mathrm{~kg}$ of milk (Lower Saxony); and 75 dairy cows/farm, 8,611 kg of milk (North Rhine-Westphalia)] and the Netherlands (87 cows per farm, $8,523 \mathrm{~kg}$ of milk).

\section{Data Collection and Description}

On-farm interviews were carried out between $\mathrm{Au}-$ gust and December 2013. Interviews were qualitative and semi-structured, and they mostly consisted of open-ended questions (Table 1). This way, all famers could express themselves in their own terms and the interviewer could follow up on possible leads in the interview (Vaarst et al., 2002). We used the same topics for discussion in each interview in both countries to make sure the information collected would be comparable. Before starting the visits to the selected farms, the interview format was tested to ensure the questions were clear and to train the interviewers (Baxter and Babbie, 2004). This validation led to slight adaptations of the questionnaire. On average, each interview was completed in about $1 \mathrm{~h}$. Generally, the decision-makers on antibiotic use were interviewed. Sometimes other people, such as the farmers' wife, parent(s), or farm employees were also present during the interviews and gave parts of answers to questions. Where useful, this information was included in the results.

Because of societal concerns, the use of antibiotics is a sensitive topic in both countries. This was taken into consideration when planning the interviews. We tried to create a natural and safe environment in which the farmers would feel free to speak openly. Two native-

Table 1. Themes discussed during the semi-structured interviews of Dutch $(\mathrm{n}=17)$ and German $(\mathrm{n}=21)$ dairy farmers

\begin{tabular}{|c|c|c|}
\hline Section & Criteria & Main question \\
\hline 3. Duration of treatment & $\begin{array}{l}\text { Number of days, milkings, } \\
\text { intramammary tubes } \\
\text { Extended treatment routine, occasional, } \\
\text { or never } \\
\text { Clinical aspects; recurrent mastitis, } \\
\text { presence of flakes, historic SCC level }\end{array}$ & When do you stop treatment? \\
\hline 4. Changes in treatment protocol & Triggers, reasons for change, compliance & $\begin{array}{l}\text { Did you always use your current treatment } \\
\text { protocol? }\end{array}$ \\
\hline 5. Social groups, interaction, and positive reference & $\begin{array}{l}\text { Awareness of what others say or do, } \\
\text { how they know, positive references (how, } \\
\text { when, effects) }\end{array}$ & $\begin{array}{l}\text { When and with whom do you talk about } \\
\text { animal health and mastitis? }\end{array}$ \\
\hline 8. Satisfaction with current treatments & Frustrations; ways forward & $\begin{array}{l}\text { Are you happy with your current } \\
\text { treatment protocol? }\end{array}$ \\
\hline 9. General farm related data & $\begin{array}{l}\text { Bulk milk SCC (BMSCC), 305-d milk } \\
\text { production, age }\end{array}$ & What is your average BMSCC? \\
\hline 10. What the farmer would like to share & None & Is there anything else you wish to share? \\
\hline
\end{tabular}


speaking interviewers, one in each country, performed the interviews to overcome possible language problems or cultural differences. The interviewers in both the Netherlands and Germany were students, who did not position themselves as experts. It was clearly expressed to interviewees that there were no right or wrong answers and that the interviewers were simply interested in the way the farmer was treating mastitis.

\section{Duration of Treatment}

The treatment duration indicated on the label was 1.5 to $2 \mathrm{~d}$ for the most frequently sold antibiotics in both countries, covering $>90 \%$ of total product sales (the Netherlands: FIDIN, 2013; Germany: VETIDATA, 2014; Table 2). Farmers were asked about their average treatment duration but not for the specific products used. Whether a treatment was considered extended was based on a comparison of farmers' reported average duration of treatment with the duration of treatment indicated on the label of the most frequently sold products, as indicated above. Farmers were also asked whether extended treatment was routinely (standard protocol for all cases) or occasionally (only in exceptional cases) applied.

\section{Data Analysis}

All interviews in the Netherlands were conducted in Dutch and all interviews in Germany were conducted in German. They were recorded on tape and fully transcribed. The data from the transcribed interviews were ordered and analyzed to identify common patterns and social groups influencing the farmers' decision. Where applicable, results were quantified to obtain an overview of the results in both countries. Data analysis was based on the grounded theory analysis (Strauss and Corbin, 1990) and the 4-step methodology of Wester and Peters (2004). According to those authors, there is a sequence to data analysis, which we followed: data exploration, which is followed by theme or concept identification, and last, theory formulation. To facilitate the analysis, a coding system was developed in which the interviews received a unique country code (the Netherlands, NL; Germany, DE), followed by the interview number, (1, 2,3 , and so on), and a letter $(\mathrm{A}, \mathrm{B}, \mathrm{C})$ for the related theme or concept. The results are illustrated with quotes derived from the interviews. The quotes were translated to English as literally as possible.

\section{RESULTS AND DISCUSSION}

The aim of this study was to explore factors influencing farmer decision-making on the duration of antibiotic treatment of clinical mastitis of dairy cows in the Netherlands and Germany. Seventy-two farms were contacted to participate in the study. The acceptance rate of participation was $52 \%$ (38 farmers were interviewed, 17 in the Netherlands and 21 in Germany). Farm and mastitis treatment characteristics per farm within countries are shown in Tables 3 and 4.

\section{Extended Treatment Occurs Frequently}

On 37 of the 38 farms, the duration of treatment was reported to be occasionally or frequently extended (Tables 3 and 4). Most farmers extended clinical mastitis treatment, either as a routine, for the majority of cases ( $\mathrm{n}=30)$, or occasionally; that is, in clinically severe cases $(n=7)$. Only one Dutch farmer told the interviewer that he never extended treatment. We found no relation between extending treatment and farm size,

Table 2. Top 8 most frequently sold products in Germany and the Netherlands registered for the treatment of clinical mastitis, their market share, and their approved number of days of treatment of clinical mastitis ${ }^{1}$

\begin{tabular}{|c|c|c|c|c|c|}
\hline \multicolumn{3}{|c|}{ Germany } & \multicolumn{3}{|c|}{ The Netherlands } \\
\hline Product & $\begin{array}{c}\text { Market } \\
\text { share (\%) }\end{array}$ & $\begin{array}{c}\text { Treatment } \\
\text { duration }(\mathrm{d})\end{array}$ & Product & $\begin{array}{c}\text { Market } \\
\text { share (\%) }\end{array}$ & $\begin{array}{c}\text { Treatment } \\
\text { duration }(\mathrm{d})\end{array}$ \\
\hline 1 & 33 & 1.5 & 9 & 46 & 1.5 \\
\hline 2 & 15 & 2 & 10 & 31 & 2 \\
\hline 3 & 15 & 2 & 11 & 15 & 1.5 \\
\hline 4 & 12 & 2 & 12 & $\mathrm{NA}^{2}$ & 1.5 \\
\hline 5 & 6 & 1.5 & 13 & NA & 2 \\
\hline 6 & 6 & $1-4$ & 14 & NA & 2 \\
\hline 7 & 2 & 2 & 15 & NA & $3^{3}$ \\
\hline 8 & 2 & 3 & 16 & NA & 2 \\
\hline
\end{tabular}

${ }^{1}$ In total, these products represent $91 \%$ of the market in Germany (VETIDATA, 2014) and 92\% of the market in the Netherlands (FIDIN, 2013).

${ }^{2} \mathrm{NA}=$ not available.

${ }^{3}$ Maximum duration of treatment is $3 \mathrm{~d}$. 
Table 3. Descriptive data of 21 German farmers, their farms, and mastitis treatment characteristics as indicated by the farmer at the time of the interview

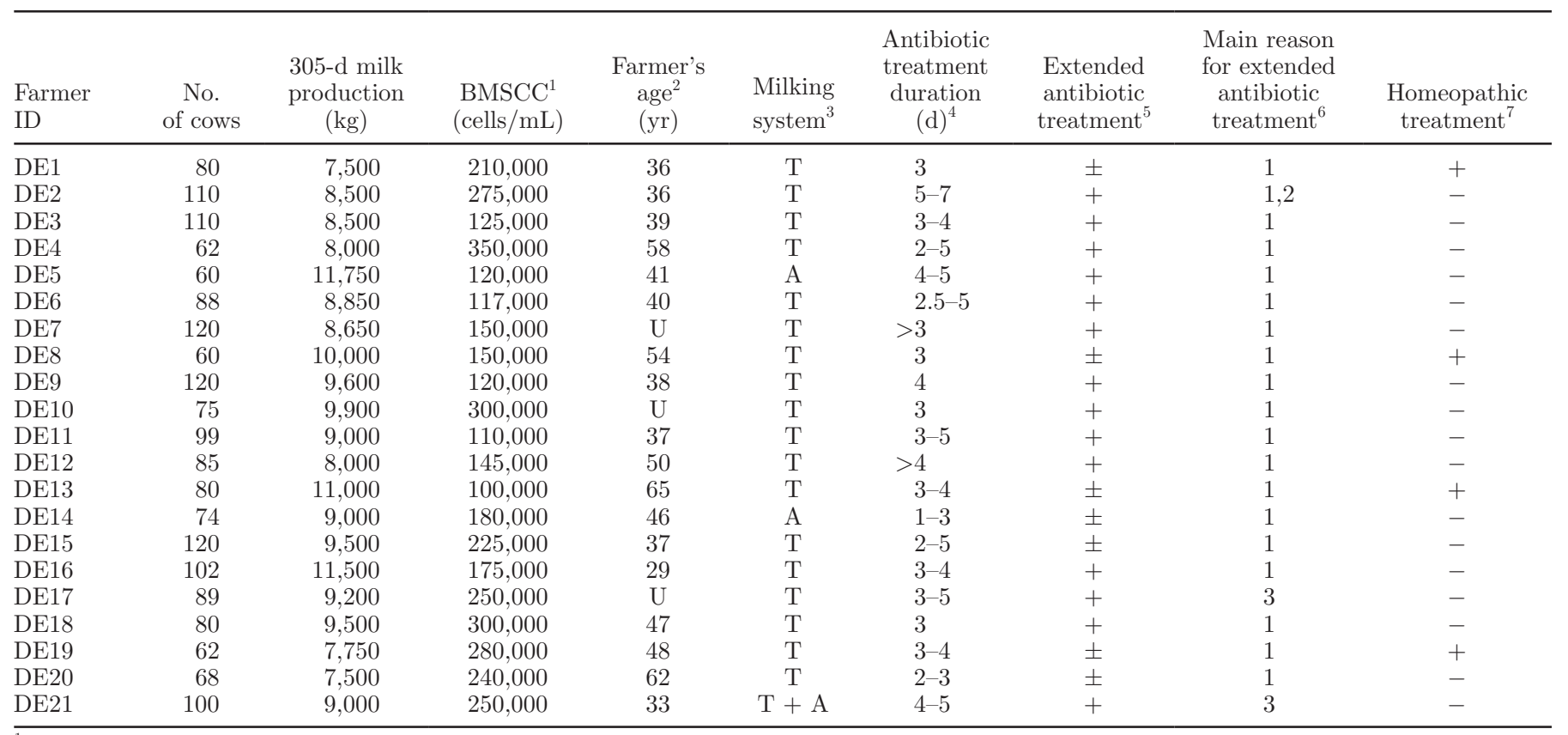

${ }^{1}$ BMSCC $=$ bulk milk SCC

${ }^{2} \mathrm{U}=$ unknown.

${ }^{3} \mathrm{~A}=$ automatic milking system; $\mathrm{T}=$ traditional milking system (any nonautomatic milking machine system).

${ }^{4}$ Number of days indicated as the most frequently used duration of treatment of clinical mastitis.

${ }^{5}$ Extended antibiotic treatment is treatment length longer than label claim; $+=$ applied on the majority of clinical mastitis cases; $\pm=$ applied occasionally.

${ }^{6}$ Where 1 = insufficient cure of clinical symptoms; $2=$ fear that mastitis returns; $3=$ standard protocol.

${ }^{7}$ Where $+=$ standard therapy; $-=$ never used.

farmer's age, milk production level, bulk milk SCC (BMSCC), or milking system (Tables 3 and 4). The interviewees were generally in the habit of extending antibiotic treatments, which suggests that this behavior is socially accepted and that it is independent of other farm-related variables. The main reasons for extending treatment retrieved from the interviews were that clinical symptoms were still present or fear of recurrence, behavior of other farmers, and recommendations of local veterinarians.

\section{Cow-Based Reasons for Extended Treatment}

Clinical Symptoms. The most frequently reported reason for extending antibiotic treatment of clinical mastitis was that the clinical symptoms had not disappeared at the completion of the label protocol (Germany; 15/21; the Netherlands; 12/17).

DE2: "At the moment I prepare a cow for milking I decide whether to stop treatment. If I still see flakes or watery milk, or the udder is still hard, we continue treatment. We usually need 5 to $7 \mathrm{~d}$; if not cured then, we continue treatment."

Four farmers, 2 in Germany and 2 in the Netherlands, reported extended antibiotic treatment as a standard therapy, irrespective of clinical symptoms. Fear that symptoms of mastitis would recur as the main reason for extending treatment was reported more frequently in the Netherlands $(\mathrm{n}=8)$ than in Germany $(\mathrm{n}=1)$. Interestingly, for dairy farmers, cure is defined both by disappearance and by nonrecurrence of clinical symptoms. In many interviews, farmers expressed using their many years of experience in judging clinical signs as a basis for deciding on the best treatment. For them, relying on experience is more important than scientific evidence (Friedman et al., 2007). This empirical experience is thought to be based on the ability to predict prognosis, based on former success and failure (Vaarst et al., 2002).

Previous research has shown that farmers experience insecurity about how to treat mastitis (Jansen and Lam, 2012). This insecurity may fuel extending 
Table 4. Descriptive data of 17 Dutch dairy farmers, their farms, and mastitis treatment characteristics as indicated by the farmer at the time of the interview

\begin{tabular}{|c|c|c|c|c|c|c|c|c|c|}
\hline $\begin{array}{l}\text { Farmer } \\
\text { ID }\end{array}$ & $\begin{array}{c}\text { No. } \\
\text { of cows }\end{array}$ & $\begin{array}{l}\text { 305-d milk } \\
\text { production } \\
\quad(\mathrm{kg})\end{array}$ & $\begin{array}{l}\mathrm{BMSCC}^{1} \\
\text { (cells } / \mathrm{mL})\end{array}$ & $\begin{array}{c}\text { Farmer's } \\
\text { age } \\
\text { (yr) }\end{array}$ & $\begin{array}{l}\text { Milking } \\
\text { system }^{2}\end{array}$ & $\begin{array}{c}\text { Antibiotic } \\
\text { treatment } \\
\text { duration } \\
(\mathrm{d})^{3}\end{array}$ & $\begin{array}{c}\text { Extended } \\
\text { antibiotic } \\
\text { treatment }^{4}\end{array}$ & $\begin{array}{l}\text { Main reason } \\
\text { extended } \\
\text { antibiotic } \\
\text { treatment }^{5}\end{array}$ & $\begin{array}{c}\text { Homeopathic } \\
\text { treatment }^{6}\end{array}$ \\
\hline NL2 & 110 & 9,000 & 150,000 & 44 & $\mathrm{~T}$ & $>1.5$ & + & 1,2 & - \\
\hline NL3 & 115 & 9,500 & 200,000 & 64 & $\mathrm{~A}$ & 3 & + & 1 & - \\
\hline NL4 & 85 & 9,000 & 140,000 & 49 & $\mathrm{~T}$ & 3 & + & 1,2 & - \\
\hline NL7 & 90 & 8,700 & 100,000 & 44 & $\mathrm{~T}$ & 2 & + & 1 & - \\
\hline NL8 & 65 & 9,171 & 180,000 & 48 & A & 3 & + & 3 & - \\
\hline NL9 & 58 & 8,100 & 200,000 & 50 & $\mathrm{~T}$ & $3-5$ & + & 2 & - \\
\hline NL10 & 80 & 8,600 & 140,000 & 48 & $\mathrm{~T}$ & 4 & + & 2 & - \\
\hline NL11 & 150 & 10,500 & 180,000 & 51 & A & 2 & - & NA & - \\
\hline NL12 & 55 & 10,000 & 100,000 & 40 & $\mathrm{~T}$ & $\geq 3$ & + & 1,2 & - \\
\hline NL13 & 85 & 8,500 & 180,000 & 54 & $\mathrm{~T}$ & $3-4$ & + & 1,2 & - \\
\hline
\end{tabular}

${ }^{1} \mathrm{BMSCC}=$ bulk milk SCC.

${ }^{2} \mathrm{~A}=$ automatic milking system; $\mathrm{T}=$ traditional milking system (any nonautomatic milking machine system).

${ }^{3}$ Number of days indicated as the most frequently used duration of treatment of clinical mastitis.

${ }^{4}$ Extended antibiotic treatment $=$ treatment length longer than label claim $;+=$ applied on the majority of clinical mastitis cases, - not applied.

${ }^{5} \mathrm{NA}=$ not applicable because extended treatment was never used; $1=$ cure of clinical symptoms; $2=$ fear that mastitis returns; $3=$ standard protocol.

${ }^{6}$ Where $\pm=$ applied occasionally and $-=$ never used.

treatment as long as clinical symptoms are visible or to prevent symptoms from recurring. We hypothesize that giving the perceived best possible treatment makes farmers feel more secure about their treatment decisions and gives them the feeling of being a "good farmer." This is perceived as the reward for extending treatment. Interestingly, none of the farmers expressed concern about the increased costs of extended treatment due to more waste milk and higher antibiotic use, nor did anyone associate the potential hazard of prolonged exposure of pathogens to antibiotics (i.e., potentially evoking antibiotic resistance). This indicates that these disadvantages were not perceived to be relevant. If our hypothesis that extended treatment is rewarded through reducing insecurity on the treatment outcome is correct, this emotional reward apparently outweighs the associated higher costs and the potential risk of antibiotic resistance development.

Clinical Versus Bacteriological Cure. As described above, for farmers, the time needed for clinical cure seems to determine treatment duration. Guidelines for efficacy studies for registration of intramammary tubes, however, indicate that bacteriological cure is considered the key parameter in evaluating success of treatment (CVMP, 2013). Clinical cure may occur at a later stage than bacteriological cure because removal of the inflammatory debris from the udder may take more time than the killing of bacteria, and may depend on the pathogen involved (Schukken et al., 2011). This discrepancy between label claims and farmers' perceptions of cure seems to contribute to a tendency to extend antibiotic treatment. In addition, scientifically, it is unclear what the best parameters are to decide when to stop or when to extend a clinical mastitis treatment. For mild gram-negative clinical mastitis cases, it has been shown that clinical improvement is a better indicator for bacteriological cure than clinical cure as such (Schukken et al., 2011). Thus, perhaps, treatment should be stopped as soon as clinical symptoms diminish. More research on the evolution of clinical criteria or on the development of practical on-farm diagnostic tests indicating bacteriological cure during treatment is needed.

\section{Farmers' Attitudes Toward Treatment or Culling}

Some interviewees indicated that they extended treatment of clinical mastitis to prevent mastitis from recurring. We found that interviewees used 2 approaches toward cows with recurrent mastitis. Eight of the interviewees considered it good stockmanship to aim for cows with greater longevity. For those farmers, to achieve that, treatment of clinical mastitis, including recurrent cases, needed to be as good as possible: 
NL12: "For me, it is a priority that cows grow old. Without antibiotics, that is not possible. I think that farmers who are really careful with their cows have older animals. And I also think that, on average, they use more antibiotics."

The other approach, expressed by 4 farmers, was to cull recurrent cases at an early stage:

NL7: "If you want to work economically, you should get rid of problem cows. Now, I cull cows if they are suffering from mastitis twice in one lactation. In this way, after a number of years, a group is selected that can handle it. A group that does not suffer from mastitis."

These 2 different attitudes toward the treatment of recurrent mastitis cases may be the result of how strongly farmers are attached to their cattle (Bock et al., 2007). Bock et al. (2007), for example, distinguished "attached" from "detached" farmers. Those who strive for greater longevity may be more emotionally attached to their animals and more cow-oriented than those who have a less emotional (detached) and more businessoriented approach toward animals, resulting in culling cows at an earlier stage. Generally, dairy farmers' attitudes may be an important predictor for antibiotic use, as has been described for mastitis incidence (Jansen et al., 2009). Cow-oriented farmers probably use more antibiotics and tend to extend treatment more often than do business-oriented farmers.

\section{Influence on Treatment Decisions by Social Reference Groups}

People are continuously socially influenced by other people, by what they do, what they say, and what they do not say. What others do provides social proof regarding what is appropriate or inappropriate behavior in a given situation (Cialdini, 1984; Cialdini and Goldstein, 2004). Social influence occurs when people look for social norms of others (Turner, 1991). It is based on the tendency of people to conform to positive rather than to negative expectations of others (Deutsch and Gerard, 1955). To reduce social uncertainty, people compare themselves to social norms of other groups (Abrams and Hogg, 1990), and group pressure makes such beliefs stronger (Festinger, 1950). The closer to oneself a reference group is perceived to be, the higher the social influence of that group is on one's own behavior (Festinger, 1954). Personal identification with a reference group allows social norms to be exchanged and to serve as a reference for behavior.
In the interviews, 5 main stakeholders were identified as social groups that have normative influence on dairy farmers' clinical mastitis treatment decisions: their veterinarian, other advisors such as a nutritionist, other dairy farmers, meat-producing farmers, and society. Media, government, regulators, and policymakers are all considered as part of society. Table 5 presents perceived positive and negative reference groups of the dairy farmers in the study. A positive reference group is a group that one accepts, identifies with, and feels psychologically attracted to (Turner, 1991). Table 5 shows that the veterinarian, other advisors, other dairy farmers, and meat-producing farmers are perceived as positive reference groups. These positive reference groups coincide with the groups that regularly come on farm. Farmers seem to identify with people close to themselves, with whom they have face-to-face contact, resulting in positive reference and, finally, social influence. A negative reference group is a group of people that one rejects and does not want to belong to (Turner, 1991). Table 5 shows that society was perceived only as a negative reference group by the interviewees, and not as a positive reference group. This indicates that the farmers in the study rejected the social norms of society; that is, the societal perception that farmers use too many antibiotics.

Positive Reference by Behavior of Other Farmers. People, including dairy farmers, generally categorize themselves by identifying or not identifying themselves with social norms of groups of people (Turner, 1991). By showing their approval or disapproval toward norms of other farmers, such as expressing that they have mastitis problems in their herds, or that they readily treat recurrent cases of mastitis or use antibiotics preventively, they categorize themselves and thereby identify who they are and what they think. Because other dairy farmers are generally a positive reference group very similar to themselves, dairy farmers want to

Table 5. Positive and negative reference groups of dairy farmers related to antibiotic treatment of clinical mastitis

\begin{tabular}{|c|c|}
\hline Negative reference group & Positive reference group \\
\hline $\begin{array}{l}\text { Meat producers }{ }^{1} \\
\text { Other dairy farmers }{ }^{3} \\
\text { Society }\end{array}$ & $\begin{array}{l}\text { Meat producers }{ }^{2} \\
\text { Other dairy farmers } \\
\text { Local veterinarian } \\
\text { Other advisors }\end{array}$ \\
\hline
\end{tabular}

${ }^{1}$ In the context of quantities of antibiotics used and of preventive versus curative use of antibiotics.

${ }^{2}$ In the context of the perception of society that farmers use too many antibiotics.

${ }^{3}$ Other dairy farmers who say they never have mastitis problems in their herds and farmers who have a different approach in decisionmaking of treatment versus culling.

${ }^{4}$ All other dairy farmers, except those mentioned in footnote 3 . 
conform to the norms of other dairy farmers (Festinger, 1954). This means that dairy farmers are sensitive to what other dairy farmers say and do:

DE9: "I think there is not a lot of difference in the way farmers treat mastitis."

Extending treatment of clinical mastitis was considered a "thorough" approach by many interviewees. This shows, from an interviewee's point of view, good stockmanship and that animals are properly taken care of. The fact that 30 out of 38 interviewed farmers said so shows this to be a social norm that may also apply to other dairy farmers. It confirms the findings of a study on mastitis treatment decisions by Vaarst et al. (2002), which showed that farmers are intrinsically motivated to control animal health and associate it with good stockmanship, which strengthens their pride. Additionally, Dutch dairy farmers were found to experience insecurity about the cure of a mastitis case (Jansen and Lam, 2012), which may lead to perceived stress when treating clinical mastitis, as was explicitly expressed by one of the German interviewees:

DE9: "Nothing is more annoying than a cow with mastitis. The milk is gone and you have the stress of treatment."

Another source of insecurity is the risk of recurrence of clinical mastitis after treatment, which may encourage extended treatment. Insecurity may make farmers sensitive for what other farmers do or not do:

NL15: "You should treat it well and long. You should not stop the treatment too early. Some farmers always treat mastitis only for three days. But then mastitis will return. Therefore we concluded that you should extend the treatment, certainly if you deal with aureus, Staphylococcus aureus."

The interviewed farmers in Germany and the Netherlands had clear perceptions of what a good farmer is and they clearly strive to be recognized as such by other farmers. This need for recognition is not a specific need of farmers - it is a universal need for all humans (Taylor, 1992). Extended treatment was associated with not feeling guilty if mastitis recurs after all. It provided a sense of responsible behavior, as the following comment by of one of the German interviewees illustrates:

DE5: "We have a low BMSCC, a very good udder health and I want to keep it that way. I told them (other farmers, the vet) that when a cow gets clinical mastitis she must cure for $100 \%$ as soon as possible, because then mastitis does not recur and the cow is not able to spread the germs around. Only then I have peace of mind. Makes me feel good."

The interviews clearly reveal an important social norm for these dairy farmers (the interviewees): to try to be a "good farmer," and someone who takes good care of his or her animals. Expressing problems, concerns, and uncertainty may be (mis)interpreted by other dairy farmers as signs of being a "bad farmer":

NL7: "Sometimes I talk about mastitis problems with friends. But you do not tell everybody. You will never say to everybody; 'Hey guys, listen, I really have a lot of cows suffering from mastitis.' You know for yourself, if you just ask someone, they do not always tell the truth. If you know one another well, you may talk about it. Then you ask, how do you cope with it? You will not tell a complete stranger that you have a lot of problems with mastitis. Then your good workmanship is questioned."

For the interviewees, admitting that your cows are suffering from mastitis may cause other farmers to think you are a "bad farmer," which in turn increases the risk of social sanctions. To prevent this from happening, most of the interviewed farmers were inclined not to discuss their mastitis problems with other farmers.

Positive Reference by Veterinary Recommendations. Social influence occurs when people are looking for trustworthy information on specific subjects (Deutsch and Gerard, 1955; Cialdini and Goldstein, 2004). The interviewees perceived veterinarians and other advisors as reliable sources of technical information on mastitis treatment. In the interviews, farmers expressed that, in the field of mastitis, they considered the information of the veterinarian to be more valuable than that of other advisors. This confirms findings of other authors (Raymond et al., 2006; Jansen et al., 2008) that mastitis-related information of local veterinarians is generally considered trustworthy and valuable:

NL8: "If you are on a dairy fair and talk to salesmen, you usually get a biased story about medication. They say their product is really great. Then you ask your veterinarian, what kind of medication is this? He knows more about the background of the product." 
This quote suggests that the social influence of the veterinarian is informational rather than normative. However, extending treatment is sometimes reinforced by veterinarians, which can be perceived as normative social influence. In 5 of the Dutch and 4 of the German interviews, the farmer spontaneously indicated that extending mastitis treatment was initiated because the herd veterinarian advised so:

NL6: "Ten years ago, a veterinarian from the drug company told me 3 tubes was sufficient, even when flocks were still visible. I have been in doubt on this, not sure whether this was good, but eventually it turned out to be OK. Last year my own vet advised me to use 6 tubes, he told me you always have to finish the course of treatment. He said, just use a double dose, that is better than an additional injection in the neck. This is the advice of the vet, these things change over time."

In both the Netherlands and Germany, pharmaceutical companies or distributors sell antibiotics for mastitis treatment directly to local veterinarians. Veterinarians in these countries make money on the products sold to farmers and thus, extending the treatment of mastitis increases the income of veterinarians. We expected this to be mentioned in the interviews. Remarkably, dairy farmers never mentioned that veterinarians might also have a financial interest in advising to extend treatment of clinical mastitis. Because the veterinarian is perceived to be a positive reference, their advice to extend treatment confirms the farmer's own idea that it is better to treat longer. The veterinarians' approval strengthens the farmers' perception that extended treatment is good stockmanship. Although not in the scope of this study, veterinarians' perceptions on prescribing antibiotics (De Briyne et al., 2013; Gibbons et al., 2013) are important too, to fully understand treatment decisions of farmers.

Reference Groups Are Heterogeneous. We found that reference groups were not necessarily homogeneous and were not always judged in the same way by interviewees. When other dairy farmers, who were generally perceived as a positive reference group, stated that they never have mastitis problems in their herds, they were seen as untrustworthy and, consequently, as a negative reference group. In the same way, dairy farmers who have a different attitude toward treatment versus culling of recurrent mastitis cases, as described above, may be perceived as a negative reference group. In the interviews, meat-producing farmers, particularly in the pig, poultry, and veal calf industries, were generally seen as a positive reference group because they were perceived as colleagues. However, they were per- ceived as negative in reference to antibiotic reduction programs. They were perceived to use more antibiotics than dairy farmers and to use it for prevention of disease rather than for cure:

DE1: "Livestock farmers use too much antibiotics is what the press reports. Probably not in the dairy sector, but in the poultry sector. The poultry sector cannot survive without antibiotics. If they see a sick animal, they have to treat all animals with antibiotics to improve growth. We, the dairy farmers, only use antibiotics to treat sick individual animals."

Approximately $75 \%$ of the interviewees indicated that, according to them, meat-producing farmers are the cause of antibiotic resistance, not the dairy farmers:

DE3: "It is how it is presented. The people are often told how bad things are in feedlots, in poultry farming, or in pig farming, the extreme-large scale animal husbandry. This is always bad for us, we are linked to this image, even though it is not so bad in dairy farming. In dairy farming, the milk is checked before consumption and the consumer does not have to fear antibiotic residues. This is different for meat. These large-scale farms cannot survive without antibiotics. And I think sometimes, the dairy sector has to ignore this a bit, when using mastitis antibiotics. Well, when you see the total consumption of antibiotics in food animals, a lot of antibiotics are used. But we use far less than meat producing farmers."

Negative Social Influence of Society. Conforming to group norms is reinforced by the disapproval of negative reference groups. All dairy farmers disapproved the injunctive norm of rigorous reduction of antibiotic usage in livestock farming being imposed by society in general. Outside the inner circle of positive referenced farmers and veterinarians, the external regulators (society), such as the government, are seen as a negative reference group with a different injunctive norm (Table 5).

DE9: "I will never change my treatment strategies just because my neighbor from down the road, who votes for the 'environmental friendly' political party, will come here every day, stick his long neck in my barn, and say: "what is that you have in your syringe?"'

Not agreeing with society's norm results in a polarization, mainly because society and the associated animal 
protection organizations are perceived as not recognizing good stockmanship:

NL7: "They imagine that farmers only spend their time spreading manure with a slurry tank or applying antibiotics to treat animals. They don't know any better. I think society does not really understand that it is sometimes better for the animals to be treated with antibiotics."

The perceived norms of society were rejected by the respondents because they were seen as unjustified. Moreover, it was perceived as disrespectful toward farmers' professionalism and intrinsic need to take good care of their animals. Interviewees perceived that societies' negative perceptions of them using too much antibiotics fuels the antibiotic debate, while they believed they only use antibiotics to take good care of their animals:

NL10: "They talk about sustainability. The cows should live as long as possible. And now, they are culled earlier. Because you cannot treat properly. They talk about sustainability."

If one wants to influence antibiotic usage of dairy farmers, it is important to realize how the sender of the message is referred to by the receiver of the message. For societal actors and regulators, that is likely as a negative reference group, which probably has consequences for communication to be effective. In our opinion, mutual open communication, showing understanding and respect in a dialog, is warranted to be successful. Although there seem to be shared values, such as taking good care of animals, there is a large, seemingly unbridgeable, emotional gap between society and dairy farmers, of which the latter express feeling misunderstood and not recognized for their good stockmanship. To overcome that gap, one should try to improve mutual understanding through dialog based on shared values; however, farmers also need to work more in compliance with society's perceptions (De Greef et al., 2006).

\section{Differences Between Germany and the Netherlands}

Social influences on farmers applying antibiotic treatment of clinical mastitis resulted in largely comparable responses in Germany and the Netherlands. Both governments recognize that the use of antibiotics in livestock has to be reduced and both have banned preventive use of antibiotics. Subtle differences between the countries exist, however. At the time of the interviews in the Netherlands, meat-producing farmers as well as dairy farmers actually had to reduce their use of antibiotics. The German authorities, however, chose to start their antibiotic reduction program in poultry followed by pigs and, in the future, the program may be extended to cattle. The interviews indicated that the approach in the Netherlands was considered unfair by the interviewed Dutch dairy farmers, evoking negative feelings toward society:

NL10: "The contribution of the dairy sector is only a very small part of the use in the entire livestock sector. So, in fact, the dairy sector is dragged along in the policies of antibiotic reduction, which is undeserved."

Because the antibiotic reduction program in Germany has already begun on poultry and pig farms but not yet on dairy farms, German dairy farmers are not yet required by law to reduce antibiotic use. Nevertheless, the German interviewees seem to experience some social pressure to look critically at their own antibiotic use:

DE1: "Yes, society influences my decisions on the use of antibiotics. It is better to already work a bit towards less antibiotic use than to be forced afterwards. Because then you might not be able to comply. But when they take antibiotics completely away from us, I would consider that as unjustified."

The knowledge of possible future extension of obligatory antibiotic reduction to the dairy sector allows dairy farmers in Germany time to change their behavior voluntarily. Tighter norms, not yet being legally imposed on them at the time of the interviews, seemed to result in more positive feelings among dairy farmers, meat-producing farmers, and society compared with that in the Netherlands. This milder attitude toward other social reference groups might change when German dairy farmers are required by law to change how they use antibiotics.

\section{Reflections on the Study}

By design, this study was exploratory, and the findings may not apply to the wider population of Dutch or German dairy farmers. Additional research is required to verify whether the findings apply to these populations. Moreover, because approximately half of the approached dairy farmers were willing to participate, selection bias may have occurred, potentially influencing the results (Groger et al., 1999). Antibiotic use is a sensitive topic to discuss, so dairy farmers who chose to 
take part in the study may have expressed a different attitude toward antibiotic reduction than those who declined to participate.

Nevertheless, some lessons can be learned from this study regarding the influence on farmers of reference groups and mastitis treatment norms, and what being a "good farmer" means to different people. Perceptions on the use of antibiotics in clinical mastitis may differ in different parts of Europe. It would be interesting to repeat this study in other countries of the European Union to explore whether our findings have wider relevance and could help in an international approach to optimizing antibiotic use for clinical mastitis in dairy cows.

Although extending treatment for clinical mastitis in relation to prudent antibiotic use is debatable, it is apparently the social norm of some dairy farmers. At the national level, the development of antimicrobial resistance in livestock is positively related to the quantity of antibiotics used (Chantziaras et al., 2014). From the literature, the consequences of extending treatment of individual mastitis cases, however, are not clear. Currently, some farmers treat clinical mastitis cases longer than indicated on the label because it is perceived to be better for their animals and this practice makes them feel like "good farmers." Prudent antibiotic use warrants more research, not only on the efficacy of antibiotic treatment, but also on the consequences of antibiotic treatment for the development or prevention of antibiotic resistance in bacterial pathogens.

\section{CONCLUSIONS}

The aim of this study was to explore a range of social influences on Dutch and German dairy farmers' decisions about the duration of antibiotic treatment of cows with mastitis. Results should be interpreted as indicative and verified by additional research. This study indicated that the interviewed farmers tried to be "good farmers" and, as such, were very sensitive toward social norms of other farmers. A good farmer, in their view, extends treatment because it is perceived as the social norm. Farmers in this study expressed insecurity regarding mastitis treatment efficacy; that is, whether their treatment would be effective and prevent mastitis from recurring. This insecurity made them more sensitive to the influence of positive reference groups such as other farmers and their veterinarian, and results in a social norm of extending treatment. Conforming to other farmers' injunctive ("what ought to be done") and descriptive ("what is done") norms and the veterinarians' informational norm that extended treatment is better results in social approval, reinforcing farmers' own perceptions that, in case of doubt regarding cure, treatment should be extended. The perceived reward for dairy farmers, especially for more cow-oriented farmers, of extended treatment is the reduction of insecurity through social approval of positive reference groups. This perceived social reward clearly outweighs the penalty of higher costs of more waste milk and greater antibiotic use. Changing the extended antibiotic treatment behavior of dairy farmers will likely result in social sanctions from positive reference groups for not complying to injunctive norms and will therefore be difficult to achieve. We hypothesize that legislation, if doable and controllable, will force farmers to reduce antibiotic usage. To change social norms of "thorough" treatment, new evidence-based information, communicated by a positive reference group (e.g., the local veterinarian), will be necessary. Thus, more research is needed on the efficacy of antibiotic treatment on cure and recurrence of clinical mastitis. Practical on-farm decision support, indicating when to stop treatment, such as a reduction in clinical signs or a reliable and easy to perform on-farm tests, would help in making optimal decisions on continuation of treatment.

\section{ACKNOWLEDGMENTS}

The authors thank all the farmers for their willingness to share their views with the researchers and thank Ynte Hein Schukken (GD Animal Health, Deventer, the Netherlands) for critical reading of the manuscript.

\section{REFERENCES}

Abrams, D., and M. A. Hogg. 1990. Social Identity Theory: Constructive and Critical Advances. Springer-Verlag Publishing, New York, NY.

Baxter, L. A., and E. R. Babbie. 2004. The Basics of Communication Research. Wadsworth/Thomson Learning, Belmont, CA.

Bicchieri, C., and R. Muldoon. 2014. Social norms. The Stanford Encyclopedia of Philosophy (spring 2014 ed.), Edward N. Zalta, ed. Stanford University, Stanford, CA. http://plato.stanford. edu/archives/spr2014/entries/social-norms/.

Bock, B. B., M. M. van Huik, M. Prutzer, F. Kling-Eveillard, and A. Dockes. 2007. Farmers' relationship with different animals: The importance of getting close to the animals. Case studies of French, Swedish and Dutch cattle, pig and poultry farmers. Int. J. Sociol. Agric. Food 15:108-125.

Chantziaras, I., F. Boyen, B. Callens, and J. Dewulf. 2014. Correlation between veterinary antimicrobial use and antimicrobial resistance in food-producing animals: A report on seven countries. J. Antimicrob. Chemother. 69:827-834.

Cialdini, R. B. 1984. Influence: The Psychology of Persuasion. William Morrow Company, New York, NY.

Cialdini, R. B., and N. J. Goldstein. 2004. Social influence: Compliance and conformity. Annu. Rev. Psychol. 55:591-621.

CVMP (Committee for Medicinal Products for Veterinary Use). 2013. Guidelines for the conduct of efficacy studies for intramammary products for use in cattle. Report EMEA/CVMP/ EWP/141272/2011. European Medicines Agency, London, UK.

De Briyne, N., J. Atkinson, L. Pokludová, S. P. Borriello, and S. Price. 2013. Factors influencing antibiotic prescribing habits and use of 
sensitivity testing amongst veterinarians in Europe. Vet. Rec. 173:475.

De Greef, K. F., C. Stafleu, and A. de Lauwere. 2006. A simple valuedistinction approach aids transparency in farm animal welfare debate. J. Agric. Environ. Ethics 19:57-66.

Denzin, N. K., and Y. S. Lincoln. 2000. Handbook of Qualitative Research. 2nd ed. Sage Publications Inc., London, UK.

Deutsch, M., and H. B. Gerard. 1955. A study of normative and informational social influences upon individual judgment. J. Abnorm. Psychol. 51:629-636.

European Medicines Agency (EMA). 2014. Answers to the requests for scientific advice on the impact on public health and animal health of the use of antibiotics in animals. Report EMA/381884/2014, Veterinary Medicines Division/CVMP/CHMP. EMA, London, UK

Festinger, L. 1950. Informal social communication. Psychol. Rev. $57: 271-282$.

Festinger, L. 1954. A theory of social comparison processes. Hum. Relat. 7:117-140.

FIDIN (Fabrikanten en Importeurs Diergeneesmiddelen Nederland) 2013. Veterinary medicine market information. FIDIN, The Hague, the Netherlands.

Friedman, D. B., C. P. Kanwat, M. L. Headrick, N. J. Patterson, J. C. Neely, and L. U. Smith. 2007. Importance of prudent antibiotic use on dairy farms in South Carolina: A pilot project on farmers' knowledge, attitudes and practices. Zoonoses Public Health $54: 366-375$.

Gibbons, J. F., F. Boland, J. F. Buckley, F. Butler, J. Egan, S. Fanning, B. K. Markey, and F. C. Leonard. 2013. Influences on antimicrobial prescribing behavior of veterinary practitioners in cattle practice in Ireland. Vet. Rec. 172:14.

Green, J., and N. Thorogood. 2009. Qualitative Methods for Health Research. 2nd ed. Sage Publications, Thousand Oaks, CA.

Groger, L., P. S. Mayberry, and J. K. Straker. 1999. What we didn't learn because of who would not talk to us. Qual. Health Res. 9:829-835.

Guest, G., A. Bunce, and L. Johnson. 2006. How many interviews are enough? An experiment with data saturation and variability. Field Methods 18:59-82.

Hechter, M., and K. D. Opp, eds. 2001. Social Norms. Russell Sage Foundation, New York, NY.

Jansen, J., and T. J. G. M. Lam. 2012. The role of communication in improving Udder Health. Vet. Clin. North Am. Food Anim. Pract. 28:363-379.

Jansen, J., T. J. G. M. Lam, and R. J. Renes. 2008. Mastitis control: Seize the opportunity; The role of veterinarians as effective udder health advisors. Pages 176-177 in Proc. Natl. Mastitis Counc. 47th Annu. Mtg., New Orleans, LA. Natl. Mastitis Counc., Madison, WI.

Jansen, J., C. D. M. Steuten, R. J. Renes, N. Aarts, and T. J. G. M. Lam. 2010. Debunking the myth of the hard-to-reach farmer: Effective communication on udder health. J. Dairy Sci. 93:12961306.

Jansen, J., B. H. P. van den Borne, R. J. Renes, G. van Schaik, T. J. G. M. Lam, and C. Leeuwis. 2009. Explaining mastitis incidence in Dutch dairy farming: The influence of farmers' attitudes and behavior. Prev. Vet. Med. 92:210-223.

Krömker, V., J. H. Paduch, D. Klocke, J. Friedrich, and C. Zinke. 2010. Efficacy of extended intramammary therapy to treat moderate and severe clinical mastitis in lactating dairy cows. Berl. Munch. Tierarztl. Wochenschr. 123:147-152.
Lapinski, R. R., and R. N. Rimal. 2005. An explication of social norms. Commun. Theory 15:127-147.

Leeuwis, C., and A. van den Ban. 2004. Communication for Rural Innovation: Rethinking Agricultural Extension. Blackwell Science, Oxford, UK.

Oliver, S. P., R. A. Almeida, B. E. Gillespie, S. J. Headrick, H. H Dowlen, D. L. Johnson, K. C. Lamar, S. T. Chester, and W. M. Moseley. 2004. Extended ceftiofur therapy for treatment of experimentally induced Streptococcus uberis mastitis in lactating dairy cattle. J. Dairy Sci. 87:3322-3329.

Raymond, M. J., R. D. Wohrle, and D. R. Call. 2006. Assessment and promotion of judicious antibiotic use on dairy farms in Washington State. J. Dairy Sci. 89:3228-3240.

Scherpenzeel, C. G. M., I. E. M. den Uijl, G. van Schaik, R. G. M. Olde Riekerink, J. M. Keurentjes, and T. J. G. M. Lam. 2014 Evaluation of the use of dry cow antibiotics in low somatic cell count cows. J. Dairy Sci. 97:3606-3614.

Schukken, Y. H., G. J. Bennett, M. J. Zurakowski, H. L. Sharkey, B. J. Rauch, M. J. Thomas, B. Ceglowski, R. L. Saltman, N. Belomestnykh, and R. N. Zadoks. 2011. Randomized clinical trial to evaluate the efficacy of a 5-day ceftiofur hydrochloride intramammary treatment on nonsevere gram-negative clinical mastitis. J. Dairy Sci. 94:6203-6215.

Sol, J., O. C. Sampimon, H. W. Barkema, and Y. H. Schukken. 2000 Factors associated with cure after therapy of clinical mastitis caused by Staphylococcus aureus. J. Dairy Sci. 83:278-284.

Strauss, A., and J. Corbin. 1990. Basics of Qualitative Research. Grounded Theory, Procedures and Tactics. Sage Publications, London, UK.

Swinkels, J. M., P. Cox, Y. H. Schukken, and T. J. G. M. Lam. 2013a. Efficacy of extended cefquinome treatment of clinical Staphylococcus aureus mastitis. J. Dairy Sci. 96:4983-4992.

Swinkels, J. M., V. Krömker, and T. J. G. M. Lam. 2014. Efficacy of standard versus extended intramammary cefquinome treatment of clinical mastitis in cows with persistent high somatic cell counts. J. Dairy Res. 81:424-433.

Swinkels, J. M., T. J. G. M. Lam, M. J. Green, and A. J. Bradley. 2013b. Effect of extended cefquinome treatment on clinical persistence or recurrence of environmental clinical mastitis. Vet. J. 197:682-687.

Taylor, C. 1992. The politics of recognition. Pages 25-73 in Multiculturalism: Examining the Politics of Recognition. A. Gutmann, ed Princeton University Press, Princeton, NJ.

Truchetti, G., E. Bouchard, L. DesCôteaux, D. Scholl, and J. P. Roy. 2014. Efficacy of extended intramammary ceftiofur therapy against mild to moderate clinical mastitis in Holstein dairy cows: A randomized trial. Can. J. Vet. Res. 78:31-37.

Turner, J. C. 1991. Social Influence. Brooks/Cole Publishing Company, Belmont, CA.

Vaarst, M., B. Paarup-Laursen, H. Houe, C. Fossing, and H. J. Andersen. 2002. Farmers' Choice of Medical Treatment of Mastitis in Danish Dairy Herds Based on Qualitative Research Interviews. J. Dairy Sci. 85:992-1001.

VETIDATA. 2014. Veterinärmedizinischer Informationsdienst für Arzneimittelanwendung, Toxikologie und Arzneimittelrecht. Accessed Jan. 31, 2014. http://www.vetidata.de.

Wester, F. P. J., and V. Peters. 2004. Kwalitatieve Analyse. Uitgangspunten en Procedures [Qualitative Analysis. Keynotes and Procedures]. Coutinho B.V., Bussum, the Netherlands. 